\title{
PENERAPAN DOUBLY-FED INDUCTION GENERATOR UNTUK PEMBANGKIT LISTRIK TENAGA ANGIN
}

\author{
Radita Arindya \\ Universitas Satyagama Jakarta \\ Email : raditatech@yahoo.com
}

\begin{abstract}
Wind energy has become one of the most important and promising sources of renewable energy, which demands additional transmission capacity and better means of maintaining system reliability. The evolution of technology related to wind systems industry leaded to the development of a generation of variable speed wind turbines that present advantages compared to the fixed speed wind turbines. These wind energy conversion systems are connected to the grid through Voltage Source Converters (VSC) to make variable speed operation possible. The studied system here is a variable speed wind generation system based on Doubly Fed Induction Generator (DFIG). The rotor side converter (RSC) usually provides active and reactive power control of the machine while the grid-side converter (GSC) keeps the voltage of the DC-link constant. The additional freedom of reactive power generation by the GSC is usually not used due to the fact that it is more preferable to do so using the RSC. However, within the available current capacity the GSC can be controlled to participate in reactive power generation in steady state as well as during low voltage periods. The GSC can supply the required reactive current very quickly while the RSC passes the current through the machine resulting in a delay. Both converters can be temporarily overloaded, so the DFIG is able to provide a considerable contribution to grid voltage support during short circuit periods. This report deals with the introduction of DFIG, AC/DC/AC converter control and finally the SIMULINK/MATLAB simulation for isolated Induction generator as well as for grid connected Doubly Fed Induction Generator and corresponding results and waveforms are displayed.
\end{abstract}

Keyworld : DFIG, Wind Turbin, Simulink

\begin{abstract}
ABSTRAK
Dalam beberapa tahun terakhir, energi angin telah menjadi salah satu sumber energi terbarukan yang penting dan menjanjikan. Adapun sistem ini, menuntut kapasitas transmisi tambahan dan sarana yang lebih baik untuk menjaga kehandalan sistem. Evolusi teknologi yang berkaitan dengan industri pembangkit tenaga angin berkembang dengan generasi baru dari turbin angin dengan variable kecepatan, yang mempunyai keuntungan dibandingkan dengan turbin angin dengan kecepatan tetap. Pada sistem dengan variable kecepatan, konversi energi angin terhubung ke grid melalui Voltage Sources Converters (Konverter Sumber Tegangan) untuk membuat variabel kecepatan yang dioperasikan. Sistem yang diuraikan adalah pengaturan kecepatan angin variabel menggunakan Doubly Fed Induction Generator (DFIG). Stator generator terhubung langsung ke jaringan sementara rotor, terhubung melalui sebuah converter back-to-back. Untuk dapat memanfaatkan tenaga angin secara efisien, sistem yang dapat diandalkan terdapat pada grid yang terhubung ganda pada generator induksi. Konverter sisi rotor (RSC) biasanya memberikan kontrol daya aktif dan reaktif dari mesin sementara converter grid-sisi (GSC) menjaga tegangan dari link-DC konstan. Tambahan pembangkit daya reaktif oleh GSC biasanya tidak digunakan karena lebih jika menggunakan RSC. Dalam kapasitas saat ini tersedia GSC yang dapat dikendalikan untuk penggunaan daya reaktif dalam kondisi stabil serta selama periode tegangan rendah. GSC dapat memasok arus reaktif yang dibutuhkan dengan sangat cepat sementara RSC melewati arus melalui mesin mengakibatkan waktu tunda. Kedua konverter sementara dapat terjadi kelebihan beban, sehingga DFIG ini mampu memberikan kontribusi yang cukup besar ke grid tegangan dukungan selama periode arus hubung singkat. Penelitian ini berkaitan dengan pengenalan DFIG, AC/DC/AC kontrol converter dengan simulasi SIMULINK / MATLAB untuk Induksi Generator terisolasi dengan grid terhubung Generator Induksi Ganda Fed dan hasil yang sesuai dan bentuk gelombang yang ditampilkan.
\end{abstract}

Kata kunci : DFIG, turbin Angin, Simulink 


\section{PENDAHULUAN}

Dalam beberapa tahun terakhir, energi angin telah menjadi salah satu sumber penting dan menjanjikan sebagai salah satu bentuk energi terbarukan. Evolusi teknologi yang berkaitan dengan industri pembangkit tenaga angin bertambah, dengan perkembangan turbin angin dengan variable kecepatan yang menjanjikan banyak keuntungan dibandingkan dengan turbin angin dengan kecepatan tetap. Pada sistem dengan variable kecepatan, konversi energi angin terhubung ke grid melalui Voltage Sources Converters (Konverter Sumber Tegangan) untuk membuat variabel kecepatan yang dioperasikan. Sistem yang diuraikan adalah pengaturan kecepatan angin yang bervariasi menggunakan Doubly Fed Induction Generator (DFIG). Stator generator terhubung langsung ke jaringan sementara rotor terhubung melalui sebuah converter back-toback yang dimensioned untuk berdiri hanya sebagian kecil dari generator pengenal.

Untuk dapat memanfaatkan tenaga angin secara efisien, pada era sekarang, sistem yang paling dapat diandalkan adalah grid terhubung ganda dengan generator induksi. DFIG ini membawa keuntungan dari pemanfaatan pergantian rasio dari mesin, sehingga konverter tidak perlu dinilai untuk mesin pengenal secara penuh. Converter sisi rotor (RSC) biasanya memberikan kontrol daya aktif dan reaktif dari mesin, sementara converter grid-sisi (GSC) menjaga tegangan dari link-DC konstan. Tambahan pembangkit daya reaktif oleh GSC biasanya tidak digunakan karena fakta bahwa lebih baik dengan menggunakan RSC. Namun, dalam kapasitas saat ini telah tersedia GSC yang dapat dikendalikan untuk mendukung generasi daya reaktif dalam kondisi mapan serta selama periode tegangan rendah. GSC dapat memasok arus reaktif yang dibutuhkan dengan sangat cepat, sementara RSC melewati arus melalui mesin mengakibatkan penundaan. Kedua konverter sementara mengalami kelebihan beban, sehingga DFIG ini mampu memberikan kontribusi yang cukup besar ke grid tegangan dukungan selama periode arus pendek. Artikel ini berkaitan dengan pengenalan DFIG, kontrol converter AC / DC / AC dan akhirnya simulasi SIMULINK / MATLAB untuk mengisolasi Induksi Generator serta untuk grid terhubung Doubly Fed Induction Generator dan hasil yang sesuai serta bentuk gelombang yang ditampilkan.

\section{Converter sistem kontrol}

Bagian untuk mendukung PWM converter memiliki dua konverter, satu terhubung ke sisi rotor dan lain terhubung ke sisi grid.

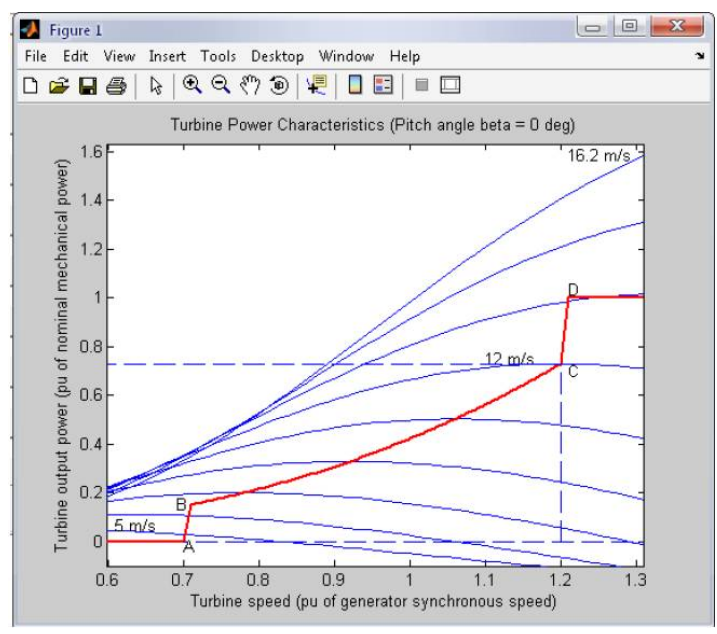

Gambar.1.Karakteristik daya pada turbin

Konverter sisi-rotor digunakan untuk mengontrol daya keluaran dan tegangan turbin angin yang diukur pada terminal grid. Daya dikendalikan untuk mengikuti karakteristik daya kecepatan yang telah ditetapkan, karakteristik tersebut dinamakan pelacakan. Karakteristik ini diilustrasikan oleh Kurva ABCD ditumpangkan dengan karakteristik tenaga mesin turbin diperoleh pada kecepatan angin yang berbeda. Kecepatan sebenarnya dari $\omega r$ turbin diukur sesuai dengan tenaga mesin. Karakteristik pelacakan digunakan sebagai referensi untuk kekuatan kontrol loop. Karakteristik pelacakan didefinisikan oleh empat point: A, B, C dan D. Dari kecepatan nol untuk mempercepat dari titik A referensi adalah nol. Antara titik A dan B titik pelacakan karakteristik berupa garis lurus. Antara titik B dan C karakteristik pelacakan adalah lokus dari kekuatan maksimum turbin (maksimum kurva daya turbin vs kecepatan turbin). Karakteristik pelacakan berupa garis lurus dari titik C dan D. Daya pada titik D adalah satu per unit. Di luar titik D kekuatan referensi adalah sama terus-menerus untuk satu per unit. 


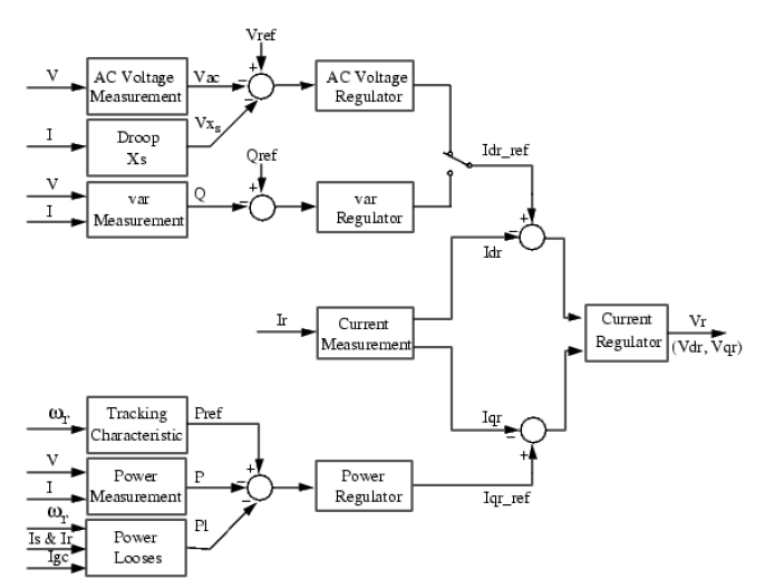

Gambar 2.Blok diagram kontrol konverter rotor

Untuk kontroler rotor-sisi sumbu-d, digunakan sebagai kerangka acuan berputar dan digunakan untuk transformasi sejalan dengan fluks gap udara. Output daya listrik yang sebenarnya diukur pada terminal grid turbin angin, yang ditambahkan dengan rugi daya total (mekanik dan listrik) dan dibandingkan dengan kekuatan referensi yang diperoleh dari karakteristik pelacakan. Sebuah regulator Proporsional-Integral digunakan untuk mengurangi kesalahan kekuatan nol.

Output dari regulator ini, adalah referensi arus rotor (Iqr_ref) yang harus disuntikkan pada rotor oleh converter $\mathrm{C}_{\text {rotor }}$. Ini adalah komponen arus yang menghasilkan torsi elektromagnetik $\left(\mathrm{T}_{\mathrm{em}}\right)$. Komponen Iqr sebenarnya dibandingkan dengan Iqr_ref dan kesalahan dikurangi menjadi nol oleh regulator (PI). Output dari kontroler adalah tegangan Vqr yang dihasilkan oleh $\mathrm{C}_{\text {rotor }}$. Regulator saat ini, dibantu oleh 'feed forward' yaitu komponen yang memprediksi Vqr. Tegangan pada terminal jaringan dikendalikan oleh daya reaktif yang dihasilkan atau diserap oleh converter $\mathrm{C}_{\text {rotor }}$. Daya reaktif yang dipertukarkan antara $\mathrm{C}_{\text {rotor }}$ dan grid, melalui generator. Dalam proses pertukaran generator untuk menyerap daya reaktif dan untuk saling memasok kebocoran induktansi. Kelebihan daya reaktif dikirim ke grid atau $C_{\text {rotor }}$.

\section{Pembuatan SIMULINK MATLAB DFIG}

Berikut akan dijabarkan pembuatan simulasi dengan menggunakan SIMULINK MATLAB, tahap pertama pembuatan simulasi ini adalah : Wind turbine driven Isolated Induction Generator model Simulation in SIMULINK, seperti terlampir pada Gambar 3.

Generator Induksi (IG) akan beroperasi jika didorong oleh variabel-pitch Turbin Angin. Kasus sebuah peternakan terdiri dari enam turbin angin 1,5-MW terhubung ke $25-\mathrm{kV}$ dengan pendistribusian kekuatan untuk grid $120-\mathrm{kV}$ melalui pengumpan $25-\mathrm{km} 25-\mathrm{kV}$. Pembangkit listrik tenaga angin 9-MW disimulasikan dengan tiga pasang turbin angin masing-masing 1,5 MW.

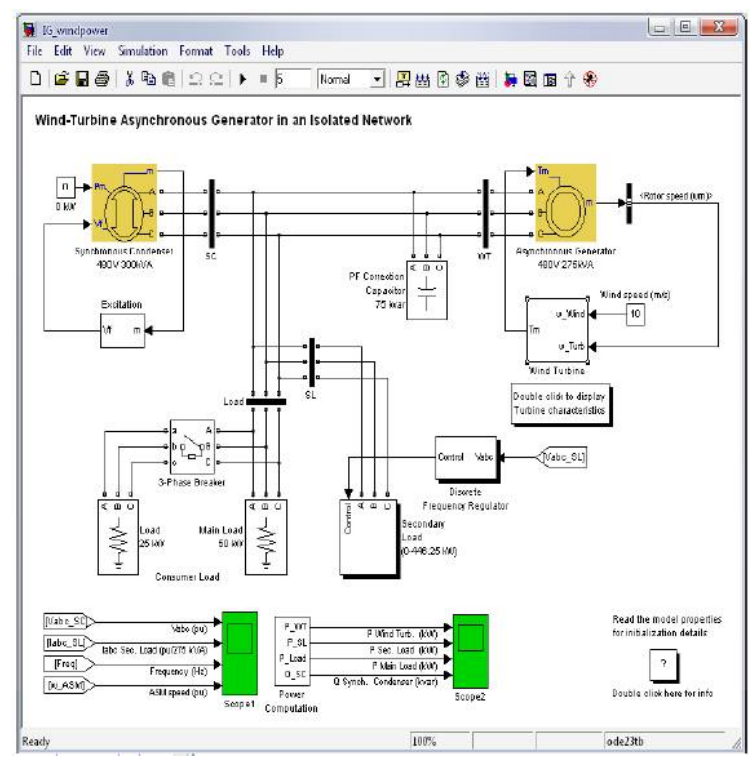

Gambar 3. Diagram SIMULINK untuk kendali Turbin Angin pada generator induksi terisolasi jenis sangkar tupai

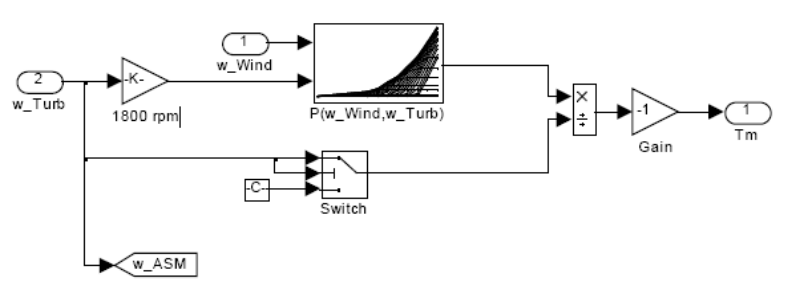

Gambar 4. Blok diagram turbin angin

Turbin angin menggunakan generator induksi sangkar tupai (IG). Stator berliku 
terhubung langsung ke jaringan $60 \mathrm{~Hz}$ dan rotor digerakkan oleh sebuah variable pitch turbin angin. Sudut pitch dikontrol untuk membatasi daya keluaran pada generator, jika nilai nominal angin melebihi kecepatan nominal $(9 \mathrm{~m} / \mathrm{s})$. Untuk menghasilkan daya, kecepatan IG harus sedikit di atas kecepatan sinkron. Kecepatan bervariasi berkisar antara 1pu tanpa beban dan 1,005 pu pada beban penuh. Setiap turbin angin memiliki sistem pemantauan perlindungan tegangan dan kecepatan. Daya reaktif diserap oleh IGS dan sebagian dikompensasi oleh kapasitor bank yang terhubung pada setiap tegangan bus turbin angin (400 kvar untuk setiap pasang turbin 1,5 MW) dan sisa daya reaktif yang diperlukan untuk menjaga tegangan $25-\mathrm{kV}$ pada bus B25 mendekati 1 pu disediakan oleh 3-Mvar STATCOM dengan pengaturan droop $3 \%$.

\section{Karakteristik output}

Karakteristik output adalah respon turbin terhadap perubahan kecepatan angin. Simulasi dimulai dengan mengamati sinyal pada "Turbin Angin", lingkup pemantauan daya aktif dan reaktif, kecepatan generator, kecepatan angin dan sudut pitch untuk setiap turbin. Untuk setiap pasang turbin, daya aktif yang dihasilkan mulai meningkat bersama dengan kecepatan angin untuk mencapai nilai dinilai dari 3 MW di sekitar 8s. Selama jangka waktu tersebut kecepatan turbin akan meningkat dari 1,0028 pu menjadi 1,0047 pu. Awalnya, sudut pitch dari bilah turbin adalah nol derajat. Ketika daya keluaran melebihi 3 MW, sudut pitch meningkat dari 0 derajat sampai 8 derajat untuk membawa daya keluaran kembali ke nilai nominal. Perhatikan bahwa daya reaktif diserap meningkat dengan meningkatnya daya aktif yang dihasilkan. Pada daya nominal, setiap pasangan turbin angin menyerap 1,47 Mvar. Untuk kecepatan angin $11 \mathrm{~m} / \mathrm{s}$, total daya yang dihasilkan diukur pada bus B25 adalah 9 MW dan STATCOM mempertahankan tegangan pada 0,984 pu dengan menghasilkan 1,62 Mvar.

\section{Proteksi Turbin Angin}

Blok Ini adalah blok untuk proteksi turbin angin terhadap tegangan dan arus. Tegangan DC diberikan sebagai masukan dan data yang berhubungan dengan nilai-nilai tersebut yang digunakan untuk melihat apakah harus diperbaiki atau tidak. Alasan yang berbeda untuk memperbaiki adalah mungkin tegangan puncak $\mathrm{AC}$, di bawah tegangan atau lebih dari saat ini, tegangan lebih, arus bawah DC, kecepatan lebih, atau kecepatan kurang.

Tergantung pada alasan tersebut di atas sinyal laju diberikan pada sirkuit dengan perjalanan waktu. Gambar wind turbin protection dapat dilihat pada Gambar 5.

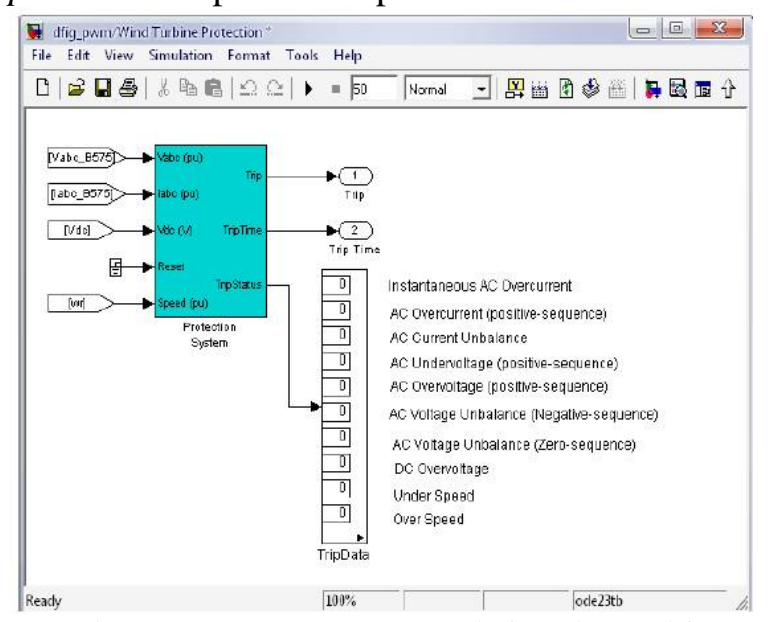

Gambar 5. SIMULINK proteksi pada Turbin Angin

\section{Akusisi Data pada Angin Turbin}

Blok diagram untuk akuisisi data pembangkit dapat dilihat pada Gambar 4 . Sinyal input tegangan dan saat ini memberikan keuntungan dan akhirnya output yang dihasilkan saat ini adalah urutan positif untuk nilai-nilai tegangan dan daya aktif dan reaktif. Dimana nilai gain

$K=[1 \exp (j * 2 * p i / 3) \exp (-j * 2 * p i / 3)]$.

Dalam blok menu turbin angin ada empat set parameter yang ditentukan untuk turbin, generator dan konverter (grid-side dan rotor-samping). 6-turbin angin pada kasus bidang pertanian disimulasikan dengan blokturbin angin tunggal dengan mengalikan tiga parameter berikut dengan enam, sebagai berikut: angin nominal mekanis keluaran turbin $=6 * 1.5 \mathrm{e} 6$ watt, ditetapkan dalam menu data pembangkit listrik Turbin yang di rata-rata menjadi $=6 * 1.5 / 0.9 \mathrm{MVA}(6 * 1,5$ MW pada pf 0,9), ditentukan dalam data menu Generator DC bus kapasitor nominal = $6 * 10000$ mikrofarad. Hal ini ditentukan dalam data Converters menu. Perhatikan pada menu kontrol parameter dalam "Mode 
operasi" diatur ke "Pengaturan tegangan" pada tegangan terminal yang akan dikontrol ke nilai yang dipaksakan dari tegangan referensi (Vref $=1 \mathrm{pu})$ dan dihasilkan rugi tegangan $(\mathrm{Xs}=$ $0,02 \mathrm{pu}$ ).

\section{Respon turbin terhadap perubahan kecepatan angin}

Dalam blok Kecepatan Angin, langkah menentukan kecepatan angin yaitu; Pertama, kecepatan angin ditetapkan sebesar 8 $\mathrm{m} / \mathrm{s}$, kemudian pada saat $\mathrm{t}=5 \mathrm{~s}$, kecepatan angin meningkat tiba-tiba menjadi $14 \mathrm{~m} / \mathrm{s}$. Kedua, simulasi dan mengamati sinyal pada ruang lingkup "Turbin Angin" kemudian memantau tegangan turbin angin, arus, daya aktif dan reaktif, tegangan DC dan kecepatan turbin yang dihasilkan. Pada saat $\mathrm{t}=5 \mathrm{~s}$, daya aktif yang dihasilkan mulai meningkat (bersamaan dengan kecepatan turbin) dan mencapai nilai 9 MW di sekitar 20s. Selama jangka waktu tersebut kecepatan turbin akan meningkat dari 0,8 ke 1,21 PU. Awalnya, sudut pitch blade turbin adalah nol derajat dan titik operasi turbin mengikuti kurva merah dari karakteristik daya turbin sampai titik D. Kemudian sudut pitch meningkat dari 0 derajad menjadi 0,76 derajad untuk membatasi tenaga mesin. Juga diamati tegangan dan daya reaktif yang dihasilkan. Daya reaktif dikendalikan untuk mempertahankan tegangan 1 PU. Pada daya nominal, turbin angin menyerap 0,68 Mvar (dihasilkan $\mathrm{Q}=-0,68$ Mvar) untuk mengontrol tegangan pada $1 \mathrm{PU}$.

\section{SIMPULAN}

Simulasi turbin angin diaktifkan secara terisolasi (tidak terhubung ke grid) untuk induksi generator. Namun untuk efisiensi terbaik sistem DFIG digunakan sistem yang terhubung ke sisi grid dan memiliki kontrol yang lebih baik. Converter sisi rotor (RSC) biasanya menyediakan daya aktif dan daya reaktif yang mengontrol mesin, sementara converter grid-sisi (GSC) menjaga tegangan dari link DC-konstan.

Pada simulasi sisi jaringan dan parameter pada sisi turbin angin, hasil yang sesuai telah ditampilkan. Model ini adalah versi diskrit dari Wind Turbin Ganda-Fed
Induksi Generator. Di sini juga digunakan sistem proteksi yang memberikan sinyal ke sistem jika ada kesalahan pada sistem. Kesalahan dapat terjadi ketika kecepatan angin menurun ke nilai rendah atau memiliki fluktuasi. DFIG ini dapat memberikan cukup kontribusi untuk dukungan pada tegangan di jaringan selama periode arus pendek. Dari simulasi disimpulkan bahwa generator induksi doubly terbukti lebih handal dan sistem yang stabil ketika terhubung ke sisi grid dengan sistem kontrol converter yang tepat.

\section{DAFTAR RUJUKAN}

Hans Øverseth Røstøen Tore M. Undeland Terje Gjengedal. IEEE paper on doubly fed induction generator in a wind turbine.

S. K Salman and Babak Badrzadeh. IEEE paper on New Approach for modelling Doubly-Fed Induction Generator (DFIG) for gridconnection studies.

Slootweg JG, Polinder H, Kling WL. Dynamic modeling of a wind turbine with doubly fed induction generator. IEEE Power Engineering Summer Meeting. Vancouver, Canada. 2001.

Holdsworth L, Wu XG, Ekanayake JB, Jenkins N. Comparison of fixed speed and doubly-fed induction wind turbines during power system disturbances. IEE Proceedings Generation, Transmission, Distribution. 2003; 3: 343-352.

Ekanayake, J.B, Holdsworth, L, Wu, X., Jenkins, N. Dynamic modeling of Doubly Fed Induction generator wind turbines. IEEE Transaction on Power Systemse. 2003; 2: 803-809.

J. Morren, J.T.G. Pierik, S.W.H. de Haan, J. Bozelie. Grid interaction of offshore wind farms. Part 1. Models for dynamic simulation. Wind Energy. 2005; 8(3).

R. Pena, J.C. Clare, G.M. Asher. Doubly-fed induction generator using back-toback PWM converters. IEE Proc.Electr. Power Appl., Vol. 143, No. 3, May 1996 